Sharif University of Technology
Scientia Iranica
SCIENTIA
IRAN Transactions B: Mechanical Engineering
www.scientiairanica.com

Research Note

\title{
Investigation of the effect of walkway orientation on natural ventilation
}

\author{
M. Rismanian ${ }^{a, *}$, A.F. Forughi ${ }^{\mathrm{b}}$, F. Vesali ${ }^{\mathrm{c}}$ and M.S. Mahmoodabadid \\ a. Faculty of Architecture, Malayer University, Malayer, Hamedan, Iran. \\ b. Faculty of Mechanical Engineering, Sharif University of Technology, Tehran, Iran. \\ c. Faculty of Railway Engineering, University of Science and Technology, Tehran, Iran. \\ d. Faculty of Architecture, Tehran University, Tehran, Iran.
}

Received 1 September 2014; received in revised form 20 April 2015; accepted 27 June 2015

\section{KEYWORDS \\ Natural ventilation; \\ Walkway orientation; \\ Free convection; \\ Sirjan; \\ Finite volume.}

\begin{abstract}
Proper orientation of walkways, based on regional winds and local shade, provides good control over walkway ventilation. The architecture of the old town of Sirjan had experimentally orientated the city's walkways in such a manner that the shadows in the walkways produced the maximum possible natural ventilation in this hot and dry town. This study has focused on the optimum design of Sirjan city considering a natural ventilation mechanism. At first, a typical walkway with certain geometric parameters is considered. Then, considering the symmetry of the shadows cast in the walkway, the natural ventilation rate is investigated at 7 different angles and at $15^{\circ}$ intervals. The problem is modeled using the finite volume method, numerically, with the climate conditions of the town. Results show that the present orientation of walkways in this city creates the maximum possible rate of natural ventilation and thermal comfort.
\end{abstract}

(C) 2016 Sharif University of Technology. All rights reserved.

\section{Introduction}

An important aspect that city designers must pay attention to is the establishment of comfortable conditions in roadways and walkways. There are several related factors, including regional climate, population density, passageway width, and building height that play a critical role in this field. Walkways and roadways usually occupy about a quarter of city spaces and have a significant effect on wind speed, moisture, and temperature distribution in an urban environment [1]. Much numerical and experimental research has been conducted to investigate comfort conditions and all factors affecting them. For instance, Niachou, Livada and Santamouris [2] used an experimental method to predict temperature and velocity distribution in

*. Corresponding author. Tel.: +989183135007

E-mail address: m.rismanian@malayeru.ac.ir ( $M$.

Rismanian) a street located in a deep narrow valley in Athens on a hot summer day. In this research, the amount of natural and hybrid ventilation was inspected in a street with specific dimensions and orientation, and results showed that the amount of natural ventilation caused by free movement in the street was so significant that it could provide proper natural ventilation. Some studies on comfort conditions in walkways have been undertaken using numerical methods. A recent work by $\mathrm{Wu}$ et al. [3] studied the effect of construction form on the natural ventilation rate using CFD simulation. Tang, et al. [4] also studied the effect of regional geometry on regional winds using the same method. Da Graça et al. [5] investigated natural ventilation in a mall area in Lisbon, Portugal, using the finite volume method. In another study, Correa et al. [6] used the COMFA method to determine comfort conditions on the Mendoza roadways in Argentina, which is placed in a forested area with low building density. Al-Sallal and Al-Rais [7] also studied the role of passive cooling 
in Dubai, as a hot and humid city, using the CFD method.

Natural ventilation as a green energy source could be useful in providing human comfort requirements in a nature-friendly manner. It is recognized that the study of factors affecting the rate of free convection could provide important data for designers to use for better design of urban walkways and roadways. One of the factors affecting the natural ventilation rate is the geometry of buildings adjacent to the walkway. Cheung and Liu [8], in a study based on the finite volume method, investigated the effect of the geometry of a building, including inlet and outlet of air, on natural ventilation. In another study, Yang et al. [9] studied the effect of tall building dimensions in Shanghai on creating the urban heat island phenomenon. This phenomenon increases the temperature in certain urban areas and, therefore, lowers the comfort conditions [10]. Tablada et al. [11] also studied the effect of building congestion on the ventilation rate of walkways in Old Havana city in Cuba. According to their conclusions, any increase in building congestion will reduce the wind flow rate and result in lower rates of air ventilation.

The other factor that highly influences the rate of natural ventilation in passageways is wind flow [13]. Mirzaei and Haghighat [12] conducted a study about the effects of building dimensions and wind flow direction on the natural ventilation rate of a street in Montreal, Canada. In another research, Tacken [13] found a relationship between the reduction of wind velocity and comfort conditions in urban areas of Holland.

Another important factor affecting natural ventilation in walkways is temperature distribution formed by shadows from neighboring buildings. Capeluto [14] investigated how building shadows affect its energy consumption. In another study, Kurazumi et al. [15] surveyed the effect of temperature distribution on thermal comfort and demonstrated the importance of this element. Safarzadeh and Bahadori [16] investigated the effect of a small building shadow on ventilation rate in its yard. Arnfield [17] claimed that the dimensions and geometric characteristics of a walkway directly affect the intensity of light in it. In some other investigations, other factors were also considered, including an important study by Shashuabar and Hoffman [18] and Part et al. [19] regarding the effect of plants and their transpiration on the ventilation rate of walkways. Their results showed that the existence of trees on sidewalks reduces the wind flow speed and temperature, thus, improving comfort conditions. In another research, Carnielo and Zinzi [10] showed that any increase in the material radiant reflection coefficient of a walkway in Rome, Italy, reduces the urban heat island phenomenon.

Correct orientation of walkways and the appro- priate design of spaces is the best way to benefit the created shade in walkways and achieve their maximum natural ventilation rate. Ali-Toudert and Mayer [20] investigated the effect of the orientation of passageways in Guardia, Argentina, using a three-dimensional numerical model of ENVI-met, and showed that the orientation and the dimensions of a walkway have a noticeable effect on its rate of natural ventilation.

The present study has studied the characteristics of the traditional city of Sirjan, Iran, using a numerical method to determine the appropriate angle of walkway orientation $(\beta)$ to get the best comfort conditions. Results show that the original designers of the walkways of this city had gained the best orientation, according to their experiences through the centuries. This paper is the first work to specify optimal orientation for walkways using CFD simulation. The novelty of this study is in the use of a more precise method to calculate fluid velocity and temperature, considering walkway orientation, and verification of the ancient architectural design.

In the following section, the geographical characteristics of Sirjan city are introduced. Then, to calculate the extent of shadows in different orientations of the sidewalks, an analytical relation is presented and the applied numerical method is reviewed. Finally, in the last section, the results are discussed.

\section{Materials and methods}

In order to study the effect of orientation of walkways on natural ventilation, the following parameters were selected for the case study: the sidewalks of the traditional city of Sirjan, Iran, at $30^{\circ} \mathrm{N}$ longitude, on the 21st day of June, at $4 \mathrm{pm}$, as the hottest day of the year [21]. For the same purpose, a sidewalk of $12 \mathrm{~m}$ in length, $2 \mathrm{~m}$ in width, and $3 \mathrm{~m}$ in height was proposed. These dimensions were supposed, since sidewalks with such dimensions were statistically more prevalent.

In Figure 1, the tree-dimensional view of the sidewalk, the path of the sun during the day, and its position at specified times have been depicted.

\subsection{Calculation of shadow dimensions}

The solar radiant flux emitted onto the surface of the walkway has a significant effect on its natural ventilation rate, and, therefore, the accurate calculation of the dimensions of the nearby shadow of the wall is very important.

In order to find the optimal orientation for the walkway, which creates the highest rate of natural ventilation, seven different orientations at $15^{\circ}$ intervals are studied. Figure 2 shows the characteristics of the shadow in a walkway during one of the hottest summer days (June 21th) at peak rush hour (4pm) in Sirjan for a flat walkway under these different orientations. So, 

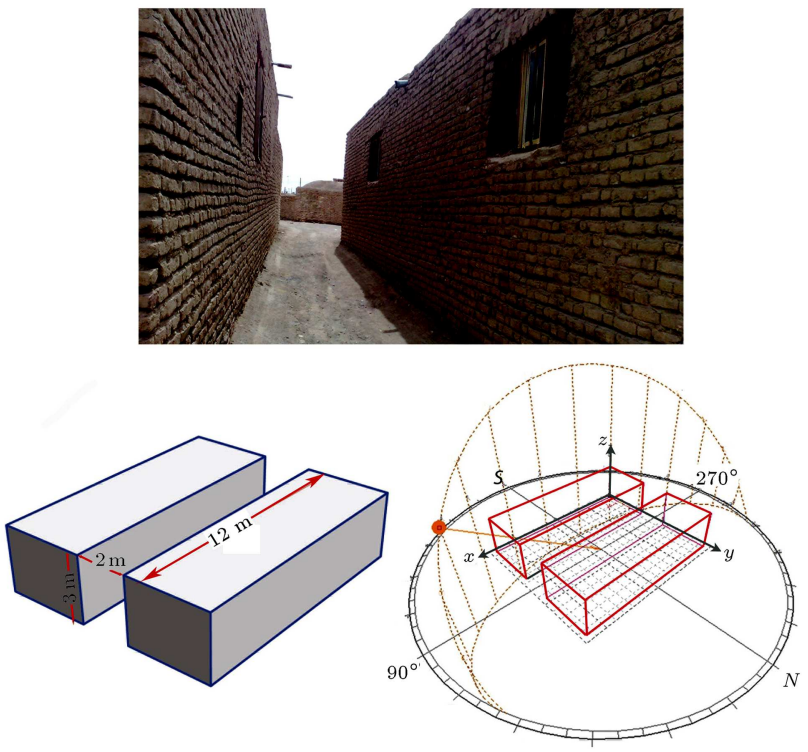

Figure 1. The sample studied walkway in Sirjan.

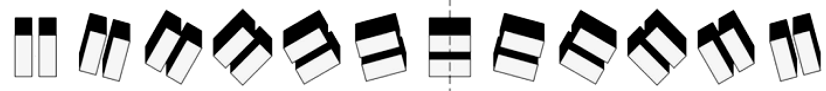

Figure 2. Shadows in the walkway plan which is drawn at $15^{\circ}$ intervals.

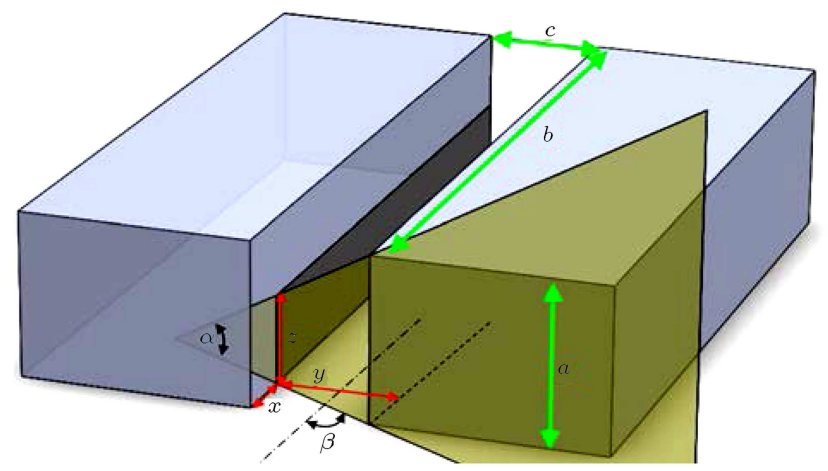

Figure 3. Shadow's dimensions in a typical walkway.

rates of shadow, solar flux projection on the sidewalk, and natural ventilation are studied for seven different orientations of the walkway.

According to the geometry of the walkway (Figure 3 ), the accurate amount of shadow size could be mathematically calculated by means of the following relations:

$$
\begin{aligned}
& z= \begin{cases}h\left(1-\frac{c}{a} \times \frac{\tan (\alpha)}{\sin (\beta)}\right), & a \times \sin (\beta)>c \times \tan (\alpha) \\
0, & a \times \sin (\beta) \leq c \times \tan (\alpha)\end{cases} \\
& y= \begin{cases}c, & a \times \sin (\beta)>c \times \tan (\alpha) \\
a \times \cot (\alpha) \times \tan (\beta), & a \times \sin (\beta) \leq c \times \tan (\alpha)\end{cases} \\
& x=c \times \cot (\beta),
\end{aligned}
$$

\begin{tabular}{|c|c|c|}
\hline \multirow[t]{2}{*}{$\begin{array}{c}\text { Walkway } \\
\text { orientation }\end{array}$} & $\begin{array}{c}\text { Geometrical } \\
\text { parameters (m) }\end{array}$ & \multirow[t]{2}{*}{$\begin{array}{l}\text { Walkway's } \\
\text { schematic }\end{array}$} \\
\hline & Heat flux $\left(\mathrm{W} / \mathrm{m}^{2}\right)$ & \\
\hline \multirow{4}{*}{$0^{\circ}$} & $x=\infty$ & \\
\hline & $y=0$ & \\
\hline & $z=0$ & \\
\hline & $q=0$ & \\
\hline \multirow{4}{*}{$15^{\circ}$} & $x=7.464$ & \\
\hline & $y=1.292$ & \\
\hline & $z=0$ & \\
\hline & $q=163.299$ & \\
\hline \multirow{4}{*}{$30^{\circ}$} & $x=3.464$ & \\
\hline & $y=2$ & \\
\hline & $z=0.597$ & \\
\hline & $q=318.431$ & Top \\
\hline \multirow{4}{*}{$45^{\circ}$} & $x=2$ & \\
\hline & $y=2$ & \\
\hline & $z=1.008$ & \\
\hline & $q=452.110$ & Top \\
\hline \multirow{4}{*}{$60^{\circ}$} & $x=1.155$ & Fro \\
\hline & $y=2$ & \\
\hline & $z=1.613$ & \\
\hline & $q=554.537$ & \\
\hline \multirow{4}{*}{$75^{\circ}$} & $x=0.536$ & \\
\hline & $y=2$ & \\
\hline & $z=1.756$ & \\
\hline & $q=618.730$ & Top \\
\hline \multirow{4}{*}{$90^{\circ}$} & $x=0$ & Front \\
\hline & $y=2$ & \\
\hline & $z=1.798$ & \\
\hline & $q=640.526$ & Top \\
\hline
\end{tabular}

Table 1. Shadow dimensions for each walkway orientation.

where parameters in Eqs. (1)-(3) are represented in Figure 3.

Table 1 represents the size of the shadow and the heat flux according to the light incidence surface of the walkway for different $\beta$.

\subsection{Mathematical modeling}

Three-dimensional equations governing fluid flow are as follows: 
Continuity:

$$
\frac{\partial u_{i}}{\partial x_{i}}=0
$$

Momentum conservation:

$$
\frac{\partial u_{i} u_{j}}{\partial x_{j}}=-\frac{1}{\rho} \frac{\partial p}{\partial x_{i}}+v\left(\frac{\partial^{2} u_{i}}{\partial x_{j} \partial x_{j}}+\frac{\partial^{2} u_{j}}{\partial x_{i} \partial x_{j}}\right)-g\left(\rho-\rho_{0}\right),
$$

Energy dissipation rate $(\varepsilon)$ :

$$
\begin{aligned}
\frac{\partial \varepsilon u_{i}}{\partial x_{i}}= & C_{\mu} \frac{k^{2}}{\varepsilon \sigma_{k}} \frac{\partial^{2} k}{\partial x_{i} \partial x_{i}}+C_{1 \varepsilon} v \frac{\varepsilon}{k}\left(\frac{\partial u_{i}}{\partial x_{j}}+\frac{\partial u_{j}}{\partial x_{i}}\right) \\
& -C_{2 \varepsilon} \frac{\varepsilon^{2}}{k},
\end{aligned}
$$

Turbulent kinetic energy $(k)$ :

$$
\frac{\partial k u_{i}}{\partial x_{i}}=C_{\mu} \frac{k^{2}}{\varepsilon \sigma_{k}} \frac{\partial^{2} k}{\partial x_{i} \partial x_{i}}+v\left(\frac{\partial u_{i}}{\partial x_{j}} \frac{\partial u_{j}}{\partial x_{i}}+\frac{\partial u_{j}}{\partial x_{i}} \frac{\partial u_{j}}{\partial x_{i}}\right)-\varepsilon,
$$

Energy conservation:

$$
u_{i} \frac{\partial T}{\partial x_{i}}=\alpha \frac{\partial}{\partial x_{i}}\left(\frac{\partial T}{\partial x_{i}}\right)
$$

where $u, x, \rho, T, v$, and $\alpha$ are the mean velocity, coordinate, density, mean temperature, viscosity and thermal diffusivity of air, respectively. The standard k-e model was used for investigation of the turbulent flow model of the problem [22]. In the above equations, $C_{1 \varepsilon}, C_{2 \varepsilon}$, $C \mu$ and $\sigma_{k}$ are 1.44, 1.92, 0.09 and 1.00, respectively [8] . A simple method was used for coupling pressure and velocity equations. The calculated temperature field, $T$, has been used to calculate the buoyancy force in the momentum equation, based on the Boussinesq approximation. Thermal boundary conditions at the walls are defined as Neumann conditions, in which the provided heat flux is calculated based on the absorbed radiation incident from the sun by considering surface properties, geological position and geometry of the surfaces. It is assumed that the surfaces not directly exposed to sunlight, are absorbing thermal radiation reflected by the other surfaces.

The equivalent area of wall exposed to the sunshine and receiving heat flux was simulated with a heat source embedded inside the wall, and the solution was carried out in a steady state. Ambient temperature was assumed to be $300 \mathrm{~K}$, and the emission of energy from the warmer wall to the front wall was ignored, due to their low temperatures. The entire region surrounding the walkway was modeled, and computational grids were generated using the Gambit package. The simulations were performed by the commercial CFD code FLUENT 6.3.26 with quadratic structural grids. We have used four different mesh sizes and repeated the simulation to achieve mesh independent results. A grid with 520000 cells was selected for our simulations.

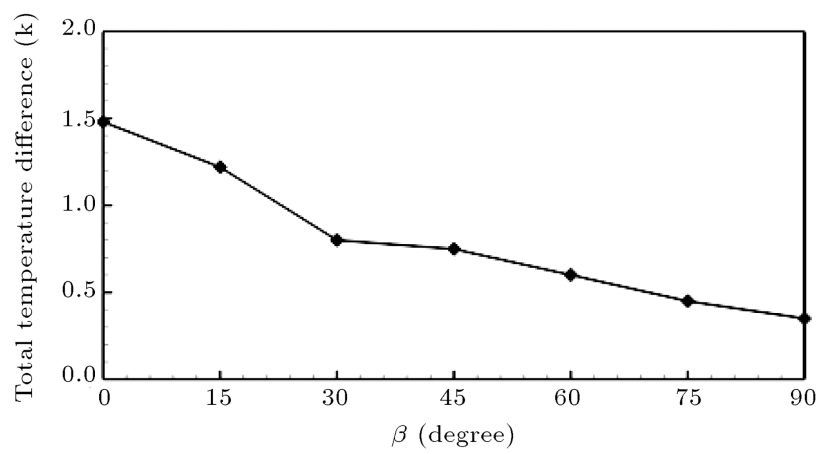

Figure 4. The temperature difference between walkway's mean temperature and ambient temperature versus $\beta$.

\section{Results and discussions}

\subsection{Temperature distribution}

Temperature distribution is the first parameter checked to discuss the effect of the orientation of the walkway on natural ventilation. The thermal layer formed on the surface is too thin, which results in most of the space of the walkway remaining at ambient temperature or close to it. Only the temperature of the air in close proximity to the surfaces with direct sunlight rises. Hence, most of the air whose temperature rises is placed in an area that would not have any effect on the comfort conditions of pedestrians.

The temperature difference between the walkway and the environment is shown in Figure 4 for different $\beta$. The largest temperature difference is caused by $\beta=$ $0^{\circ}$ and the smallest difference resulted from $\beta=90^{\circ}$. As seen, the maximum relative temperature difference with the environmental temperature is $\frac{1.58}{300}=0.53 \%$, and its minimum is $\frac{0.30}{300}=0.10 \%$. The main reason for the small difference between the mean and ambient temperatures in all cases is the thinness of the thermal boundary layer on the floor compared to the height of the walkway. The temperature of the walkway could be assumed equivalent to ambient temperature and, therefore, the effects of temperature variations at different $\beta$ on the natural ventilation of the walkway could be ignored.

\subsection{Velocity distribution}

The other studied parameter is velocity distribution in the walkway. Velocity vectors in the walkway for $\beta=$ $0^{\circ}$ have been illustrated in Figure 5 . The maximum velocity of air appears at the center of the walkway, where two flows from two ends of the walkway come across and move upwards.

Results show that streamlines correctly describe the behavior of air flow at every $\beta$ and its difference with other angles.

In order to have a qualitative investigation of velocity distribution in the walkway, maximum velocity and mean velocity in relation to $\beta$ have been shown in Figure 6. Referring to this figure, the maximum 


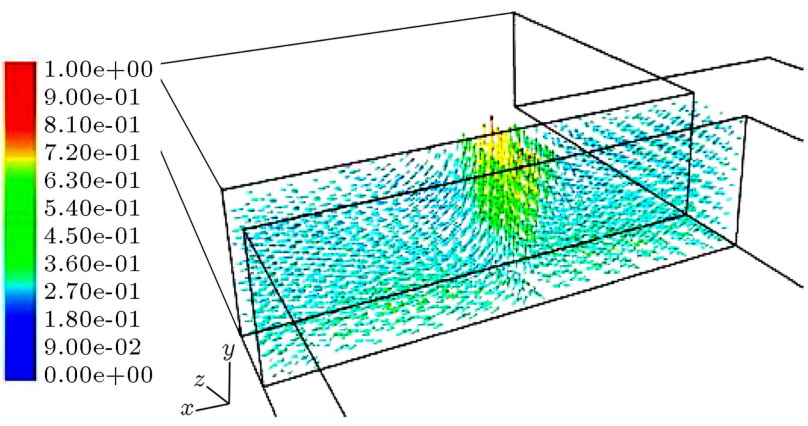

Figure 5. Air velocity vectors in the walkway for $\beta=0$.

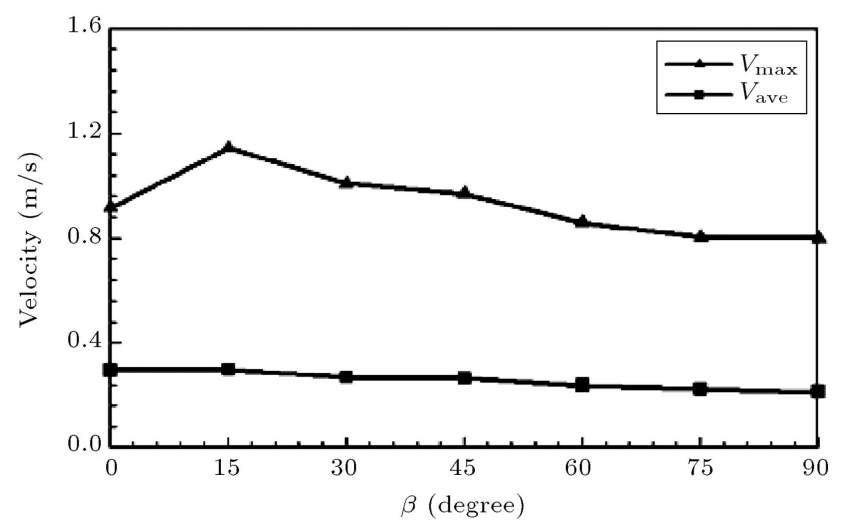

Figure 6. Maximum and mean velocity in the walkway versus $\beta$.

velocity in the walkway is reached at $\beta=15^{\circ}$, as the average velocity also has its highest value at the same angle. The flow regime at $\beta=0^{\circ}$ and $15^{\circ}$ is different from other angles because a large area of the floor is exposed to sunlight at these angles.

The increase of maximum velocity and mean velocity at these $\beta$ does not necessarily provide better ventilation in these orientations. Velocity distribution at $\beta=0^{\circ}$ and $15^{\circ}$ is less uniform than $45^{\circ}$. In fact, the warming of the floor increases the natural convection at the center and produces a high flow rate without providing any proper ventilation.

\subsection{Air discharge produced in the walkway}

The produced air flow in the walkway is another studied parameter to determine its probable effect on the natural ventilation in the walkway. Figure 7 shows the air flow rate over the walkway at different $\beta$.

According to this figure, at $\beta=45^{\circ}$, the highest air discharge is produced and also considering the distribution of velocity in the walkway space (Figure 6), the produced velocity at this $\beta$ will enjoy a uniform distribution. In other words, not only has the maximum ventilation rate in the walkway been reached, but, also, the velocity distribution is uniform and there is no trace of high local velocities. Moreover, stream lines at this angle show that the air flow uses all the upper section of the walkway for appropriate ventilation in all its places

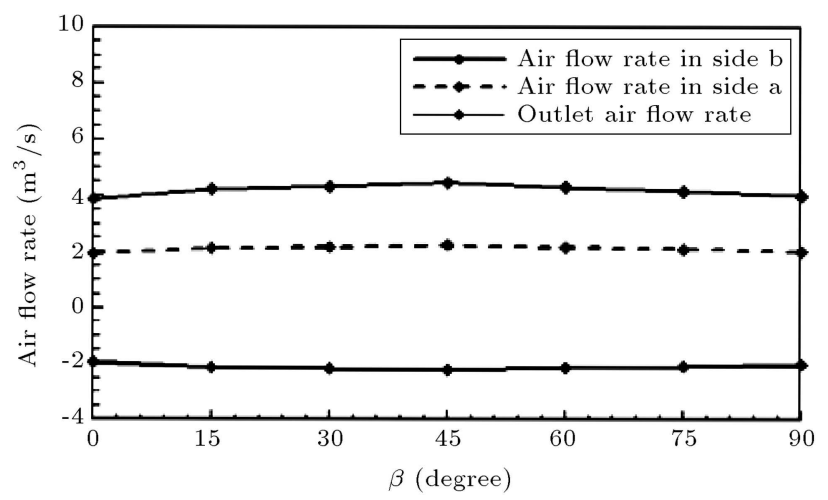

Figure 7. Air flow rate in sides a and b, and outlet air flow rate versus $\beta$. a and $b$ sides are represented in Figure 3.

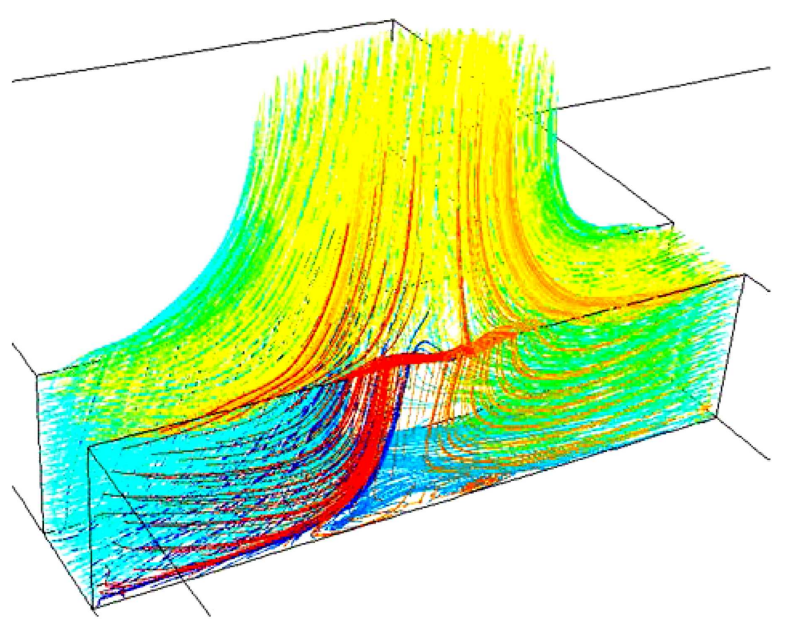

Figure 8. Streamline in the walkway at $\beta=45^{\circ}$.

(Figure 8). Also, by looking at Figure 4, it is clear that the increase of mean temperature at this $\beta$ is also lower than angles like $\beta=0^{\circ}$ and $15^{\circ}$.

So, in order to have the best ventilation in the walkway, it should be in a direction with $\beta=45^{\circ}$. This angle for this study region equals $-50^{\circ} /+40^{\circ} \mathrm{N}$ angle, which correspond to the angles of walkways in Sirjan.

\section{Conclusion}

This study investigates the effects of urban and walkway orientation on the air flow rate created by free movement in a walkway. The goal of this study was to investigate the optimal use of sunlight in order to improve comfort conditions for pedestrians. The traditional city of Sirjan, Iran, was considered as our case study. Air flow in the walkway was simulated by the computational fluid dynamics method. Then, simulation results on temperature and velocity distribution, maximum velocity and produced natural air flow in the walkway were used to compare its natural ventilation for 7 different orientations. The results show that the 
temperature of the air flowing in the walkway is to a high degree, similar to ambient temperature, and will not experience any considerable increase. Also, the maximum air ventilation in the walkway reaches its peak value when the walkway makes an angle of $-50^{\circ}$ or $+40^{\circ}$ relative to a northerly direction. The resulted comfort condition is created by the evaporative cooling effect of flowing air over the skin surface. In other words, in hot weather, sweating will decrease the human body's temperature, because air flows over the skin surface and sweat evaporation removes the heat from the skin. Therefore, the higher the intensity of flow passing over the skin, the further reduction of temperature will be achieved, and pedestrians feel better when they walk in the walkway. It is very important in hot and dry climates that more moisture from the surface of the skin is absorbed and, in consequence, a more sensible temperature drop occurs in the body. The good agreement between the results of the current study and the real walkway orientation in Sirjan shows that the designers of this town have experimentally found the best orientation for maximal natural ventilation in walkways, based on years of experience.

\section{Acknowledgment}

We would like to thank Mr. Milad Rismanian at Sharif University of Technology, Tehran, Iran, for his valuable technical support of this project.

\section{References}

1. Shashua-Bar, L. and Hoffman, M.E. "Geometry and orientation aspects in passive cooling of canyon streets with trees", Energy and Buildings, 35(1), pp. 61-68 (2003).

2. Niachou, K., Livada, I. and Santamouris, M. "Experimental study of temperature and airflow distribution inside an urban street canyon during hot summer weather conditions - Part I: Air and surface temperatures", Building and Environment, 43(8), pp. 13831392 (2008).

3. Wu, Y.-C., Yang, A.-S., Tseng, L.-Y. and Liu, C.-L. "Myth of ecological architecture designs: Comparison between design concept and computational analysis results of natural-ventilation for Tjibaou Cultural Center in New Caledonia", Energy and Buildings, 43(10), pp. 2788-2797 (2011).

4. Tang, L., Nikolopoulou, M., Zhao, F.-Y. and Zhang, N. "CFD modeling of the built environment in Chinese historic settlements", Energy and Buildings, 55(0), pp. 601-606 (2012).

5. Carrilho da Graça, G., Martins, N.R. and Horta, C.S. "Thermal and airflow simulation of a naturally ven- tilated shopping mall", Energy and Buildings, 50(0), pp. $177-188$ (2012).

6. Correa, E., Ruiz, M.A., Canton, A. and Lesino, G. "Thermal comfort in forested urban canyons of low building density", An Assessment for the City of Mendoza, Argentina. Building and Environment, 58(0), pp. 219-230 (2012).

7. Al-Sallal, K.A. and Al-Rais, L. "Outdoor airflow analysis and potential for passive cooling in the modern urban context of Dubai", Renewable Energy, 38(1), pp. 40-49 (2012).

8. Cheung, J.O.P. and Liu, C.-H. "CFD simulations of natural ventilation behaviour in high-rise buildings in regular and staggered arrangements at various spacings", Energy and Buildings, 43(5), pp. 1149-1158 (2011).

9. Yang, F., Lau, S.S.Y. and Qian, F. "Summertime heat island intensities in three high-rise housing quarters in inner-city Shanghai China: Building layout, density and greenery", Building and Environment, 45(1), pp. 115-134 (2010).

10. Carnielo, E. and Zinzi, M. "Optical and thermal characterisation of cool asphalts to mitigate urban temperatures and building cooling demand", Building and Environment, 60(0), pp. 56-65 (2013).

11. Tablada, A., De Troyer, F., Blocken, B., Carmeliet, J. and Verschure, H. "On natural ventilation and thermal comfort in compact urban environments - the Old Havana case", Building and Environment, 44(9), pp. 1943-1958 (2009).

12. Mirzaei, P.A. and Haghighat, F. "A procedure to quantify the impact of mitigation techniques on the urban ventilation", Building and Environment, 47(0), pp. 410-420 (2012).

13. Tacken, M. "A comfortable wind climate for outdoor relaxation in urban areas", Building and Environment, 24(4), pp. 321-324 (1989).

14. Capeluto, I.G. "Energy performance of the self-shading building envelope", Energy and Buildings, 35(3), pp. 327-336 (2003).

15. Kurazumi, Y., Tsuchikawa, T., Matsubara, N., Kondo, E. and Horikoshi, T. "Evaluation of enhanced conduction-corrected modified effective temperature ETFe as the outdoor thermal environment evaluation index", Energy and Buildings, 43(10), pp. 2926-2938 (2011).

16. Safarzadeh, H. and Bahadori, M.N. "Passive cooling effects of courtyards", Building and Environment, 40(1), pp. 89-104 (2005).

17. Arnfield, A.J. "Street design and urban canyon solar access", Energy and Buildings, 14(2), pp. 117-131 (1990).

18. Shashua-Bar, L. and Hoffman, M.E. "Quantitative evaluation of passive cooling of the UCL microclimate in hot regions in summer, case study: urban streets 
and courtyards with trees", Building and Environment, 39(9), pp. 1087-1099 (2004).

19. Park, M., Hagishima, A., Tanimoto, J. and Narita, K. "Effect of urban vegetation on outdoor thermal environment: Field measurement at a scale model site", Building and Environment, 56(0), pp. 38-46 (2012).

20. Ali-Toudert, F. and Mayer, H. "Numerical study on the effects of aspect ratio and orientation of an urban street canyon on outdoor thermal comfort in hot and dry climate", Building and Environment, 41(2), pp. 94-108 (2006).

21. Tabatabaee, M., Calculation of Building Air Conditioning, 7 Ed., Rouzbahan Publisher (2012) (in Persian).

22. Liu, D., Zhao, F.-Y. and Tang, G.-F. "Non-unique convection in a three-dimensional slot-vented cavity with opposed jets", International Journal of Heat and Mass Transfer, 53(5-6), pp. 1044-1056 (2010).

\section{Biographies}

Mahdi Rismanian received his BS and MS degrees in Architectural Engineering from Emam-Khomeini International University, Ghazvin, Iran, and is currently teaching architectural engineering at the University of Malayer, Hamedan, Iran. His main research interests include urban design, and architecture in achieving sustainable and green building.
Amir Farzad Forughi received his BS degree from Bu-Ali Sina University, Hamedan, Iran, and his MS degree from Sharif University of Technology, Tehran, Iran, in 2010 and 2013, respectively, both in Mechanical Engineering. He is currently a PhD degree student of Mechanical Engineering at the University of British Columbia (UBC), Vancouver, Canada, and a research assistant in the Microsystems and Nanotechnology Research Group (MiNa) at the same institution. His research focuses on optofluidics, porous media and experimental thermofluids.

Farzad Vesali was born in 1987. He holds a BS degree in Mechanical Engineering from Bu-Ali Sina University, Hamedan, Iran. He has completed a post-graduate program in Rolling Stock Engineering at the School of Railway Engineering in Iran University of Science and Technology, Tehran, Iran, and is currently a PhD degree student in the same field. His research interests include vibration and mechanism design. He is also actively involved with the study of ancient engineering and the secrets of its designs.

Mohammad Sadegh Mahmoodabadi was born in 1987. He holds a MS degree from the Art University of Tehran, Iran, and is a member of the Kerman Engineering Organization in Iran. His research interests include interior design architecture and decoding the secrets behind Iranian Islamic Architecture. 